\title{
PRÁTICA DE ENSINO DA REDAÇÃO: UMA PROPOSTA ICÔNICO- DIGITAL
}

\author{
Darcilia Simões * \\ Rosane Reis **
}

\begin{abstract}
Resumo: Este artigo apresenta proposta de ensino de redação, pautado nas competências e habilidades inscritas em documentos oficiais. Objetiva a correção de redações por meio digital que busca identificar os problemas do texto produzido pelo redator, fornecer instruções lexicais e gramaticais para correção do problema apontado e propõe reescritura para nova apreciação. A instrução gramatical incidente sobre problemas detectados no texto é subsidiada por instruções semióticas de cunho didático-pedagógico. É um trabalho de redação-correçãocomentário-reescritura por meio digital, e os problemas assinalados servem de senhas para o aperfeiçoamento do texto.
\end{abstract}

Palavras-chave: Ensino da redação. Língua Portuguesa. NTIC. Competências. ENEM.

\begin{abstract}
This article presents a proposal of teaching writing, based on skills and abilities registered in official documents. This project aims at correcting writing compositions, using digital tools, in order to identify the problems of students' texts, providing lexical and grammatical instructions to correct the problem in their texts and proposing rewriting for reconsideration. The grammar instruction placed directly adjacent to problems detected in their texts is subsidized by semiotic instructions didactic-pedagogic profile. It is a work of writingcorrect-comment-rewrite by digital tools, and the problems identified work as passwords for improvement of the text.
\end{abstract}

Keywords: Teaching writing. Portuguese. NTIC. Skills. ENEM.

\section{Palavras iniciais}

O mundo cibernético vem promovendo uma dinâmica cuja demanda exige que nós, professores de Língua Portuguesa e Redação, estejamos sempre atualizados das práticas redatoras nos ambientes virtuais, pois nossos alunos, a geração digital, estabelecem um vínculo com a Internet, lendo e escrevendo numa velocidade espantosa. Assim sendo, convém tirar-se proveito desse cenário cibernético em prol da melhoria da qualidade do ensino e da aprendizagem em todos os campos do saber, em especial, o linguístico.

Essa nova forma de comunicação acabou promovendo uma mudança significativa no campo das comunicações verbais, em especial. Como os jovens dessa nova era escrevem o dia todo, com seus dedinhos polegares na tela de seus smartphones! E com uma velocidade espantosa!

Mas o que dizer desses novos textos, desse novo gênero, desse novo vocabulário, os quais circulam livremente entre os internautas da comunicação digital? Como encarar essa nova "onda" de nossos alunos, sem criticar-lhes a forma com que fazem uso da língua? (SIMÕES; OLIVEIRA, 2014). Na contramão do que esperávamos da nova geração que não lê os clássicos da literatura, a chegada da rede mundial de computadores veio promover o retorno à redação.

A comunicação escrita nos novos aplicativos de "bate-papo" favorece a interação simultânea com mais de um interlocutor, que pode estar na sala ao lado ou em outro país. Isso, além de enriquecedor, é fascinante!

\footnotetext{
Doutora em Letras Vernáculas (UFRJ, 1994) e Pós-doutora em Semiótica e Comunicação (PUC, 2007) e Linguística (UFC, 2010). E-mail: darcilia.simoes@pq.cnpq.br

Doutora em Letras (UERJ, 2014), Membro do Grupo de Pesquisa Semiótica, Leitura e Produção de Textos. Coordenou a equipe de Redação do Sistema Elite de Ensino e criou a Central de Correções (CECOR). E-mail: reisdinamico@gmail.com
} 
Tal realidade surge num ambiente em que as formas de aprender são características de uma contemporaneidade que pressupõe rapidez de resultados, interconexão entre saberes e ações; é um mundo repleto de estímulos novos, variados e frequentes. Inseridas nessa era digital, nós (pesquisadoras e autoras do presente trabalho) apostamos em um novo modelo de interação entre professores e alunos para desenvolver-lhes a escrita, sem sair do ambiente cibernético.

Ambientes virtuais de aprendizagem que permitem a convivência, a interligação dos saberes, a troca de experiências podem ser um caminho para a formação de redatores proficientes, possibilitando aos internautas do ensino à distância um espaço para discussões, interações e comunicações de forma reflexiva. Esse espaço de experiência e de vivência certamente terá impacto no modo como aprendemos e como ensinamos redação.

Neste artigo, pretendemos demonstrar o modo como vimos trabalhando o ensino de redação em turmas preparatórias para concursos vestibulares, apresentando, passo a passo, (1) como a Teoria da Iconicidade Verbal (SIMÕES, 2009) se tornou nosso constructo teórico capaz de subsidiar uma prática didática eficiente em aulas virtuais, presenciais e mistas, (2) a metodologia proposta para o ensino da produção de textos discentes, revisitando e discutindo as competências e as habilidades linguísticas, para tirar melhor proveito das aulas de redação, (3) o modo como corrigimos as redações dos alunos e as ferramentas digitais que usamos para esse fim e (4) como a reescritura dos textos discentes pode ser eficiente estratégia para a aprendizagem da língua padrão.

\section{Contribuição da Teoria da Iconicidade Verbal}

Essa teoria, em edificação por Simões desde seus estudos de doutoramento (19881994 - UFRJ) e já divulgada sumariamente em Iconicidade Verbal. Teoria e Prática (SIMÕES, 2009), parte de postulados da teoria de Peirce. Partindo da premissa de que os recursos do raciocínio semiótico permitiriam uma orientação imagética no trato com a língua, a autora testou, inicialmente, a relação entre o verbal e não verbal na aquisição da escrita por alunos com dificuldades de diversa ordem (cf. SIMÕES, 2009b ${ }^{1}$ ). Confirmada a hipótese de que o texto escrito pode ser trabalhado como imagem, Simões passa a perseguir nova hipótese: os signos são objetos mentais corporificados nos códigos e linguagens que representam ideias e fatos (existentes e fictícias). A relação com seus referentes primários (ou objetos imediatos) constrói ícones, índices e símbolos que podem ser explorados como marcas textuais a partir das quais se produz a compreensão do texto. Estas são nada mais que signos estrategicamente colocados na superfície textual, para demarcar o tema, os subtemas e seus recortes, balizando assim a interpretação do texto, minimizando a possibilidade de extrapolação semiótica (cf. ECO, 1969).

Em Semiótica \& Ensino. Letramento pela Imagem (SIMÕES, 2009), temos:

Segundo pesquisas de alta relevância no âmbito da leitura e associadas à psicologia e à psicolinguística (cf. Kato ${ }^{60}$, 1982: 9), há unanimidade em afirmar-se que, na leitura proficiente, as palavras são lidas não letra por letra ou sílaba por sílaba, mas como um todo analisado, ou seja, por reconhecimento instantâneo e não por processamento analítico-sintético.

Há quem afirme que o reconhecimento de palavras se dá como de qualquer outro objeto (carro, árvore, criança, etc.) e, da mesma forma que podemos

\footnotetext{
${ }^{1}$ Disponível em <http://www.dialogarts.uerj.br/admin/arquivos_mdt/semiotica_\&_ensino_2009.pdf>
} 
reconhecer um objeto em sua configuração geral, é-nos possível reconhecer uma palavra através do todo (contorno, extensão, etc.) sem que se analisem suas partes. Com base nos mesmos pressupostos, é possível que se identifique uma palavra sem que enxerguemos sua totalidade, assim como é possível identificar uma árvore - num processo aparentemente adivinhatório, contudo, com alta probabilidade de acerto - enxergando-se apenas sua copa. Verifica-se assim um processo inferencial. (SIMÕES, 2009, p. 60).

Como se pode ver, a perspectiva assumida por Simões para enfrentar o ensino da escrita — seja da aquisição seja da redação — baseia-se numa hipótese imagética: o signo verbal e o texto como objetos visuais. Para Simões a iconicidade diagramática é um valor relevante quando da produção e análise dos textos. Para a autora, a iconicidade diagramática consiste na "articulação entre signos de modo a evocar, sugerir, presentificar uma ordem de raciocínio" (SIMÕES, manuscrito ${ }^{2}$ inédito). Com essa visão, a pesquisadora propõe a discussão dos signos na superfície textual, a partir de suas funções e valores, com os quais autor e leitor veiculam/negociam suas ideias, para que desenvolvam não apenas seus respectivos repertórios, mas especialmente o domínio da estruturação gramatical.

Conforme Simões (2013),

Recuando no tempo, vemos Silveira Bueno (1964, p. 194), inspirado em Grammont ${ }^{3}$, afirmar que "a poesia, para ser poesia, deve encerrar sugestões e evocações". Propomos ir além e estender a potencialidade evocativa dos signos à prosa; e mais, transbordar da prosa artística para a prosa cotidiana, referencial, informativa. Temos convicção de que um texto originado de uma seleção lexical estratégica terá maior força comunicativa que outros a que não se deu atenção maior à escolha do vocabulário (SIMÕES, 2013, p. 73).

Estendemos essa perspectiva ao nível da estruturação sintática do texto, portanto da iconicidade diagramática, considerando que a organização dos enunciados deve refletir a ordenação de nossas ideias.

Como parceiras nessa proposta, vimos testando o ensino da sintaxe pela teoria da iconicidade verbal (TIV), com foco na iconicidade diagramática sintagmática (cf. NÖTH, 1995, p. 103-4), para aperfeiçoar a aprendizagem da construção sintática dos períodos. Algumas formas linguísticas atuam como ícones ou índices de categorias ou mecanismos gramaticais, ou seja, palavras e expressões que funcionam como âncoras que definem as regras de estruturação gramatical. Veja-se o que diz Nöth (1995) sobre os diagramas sintagmáticos: "A estruturas diagramáticas que se desenvolvem na linearidade da língua referem-se principalmente às relações temporais, espaciais e conceituais." (NÖTH, 1995, p. 103-4). Para o autor, o protótipo do diagrama temporal é a narrativa clássica, porque a ordem das proposições procura representar a "ordem natural" dos eventos. Quando se dá a representação de um caminho com identificação de locais, no discurso, e os lugares representados seguem a ordem que estes se relacionam com o ponto de partida, tem-se o diagrama espacial. Por fim, é possível identificar os diagramas conceituais, mais complexos, que buscam demonstrar causalidade, sequencialidade ou hierarquia no plano dos conceitos.

\footnotetext{
${ }^{2}$ Trata-se de um trabalho sobre iconicidade diagramática que vem sendo produzido por Simões e que se encontra em estado seminal.

${ }^{3}$ Silveira Bueno reporta-se a GRAMMONT, Maurice. Essai de Psychologie Linguistique: Style et Poesie. 1950.
} 
Ensinar os fatos da língua apoiados nos valores icônicos e indiciais das formas da língua consolida uma aprendizagem pela assimilação das estratégias de estruturação verbal. Trata-se de uma proposta de ensino gramatical de base semiótica pelo qual se ensina o estudante a ler semioticamente a estruturação sintática dos períodos e, consequentemente, dos textos. Com essa estratégia didática, o sujeito aprende a seguir a iconicidade diagramática sintagmática, identificando algumas formas como pistas icônicas e indiciais ${ }^{4}$. Essas formas atuam como marcas específicas que conduzem à identificação de categorias e funções dos vocábulos, para que se possa chegar aos valores gramaticais exigidos na construção sintática dos períodos. A partir desses postulados, a Teoria da Iconicidade Verbal se tornou nosso constructo teórico capaz de subsidiar uma prática didática eficiente em aulas virtuais, presenciais e mistas; e a metodologia que propomos, para o ensino da produção de textos discentes, revisita e discute as competências e as habilidades linguísticas necessárias para a produção de textos eficientes, ou seja, que de fato realizem a comunicação entre autor e leitor.

Observamos que, mesmo com as várias técnicas já desenvolvidas em salas de aula tradicionais, quando o assunto é redação sempre há um desconforto dos alunos em apresentarem seus textos e um certo desânimo dos professores. Estes, porque corrigem centenas de produções textuais, fazendo alterações sem nenhuma explicação, apenas riscando e substituindo termos ou frases inteiras, lamentando o mau uso da língua por jovens internautas e sem compromisso com a norma culta; aqueles, porque não sabem o que motivou a alteração de seus textos, ou porque simplesmente não sabem o que escrever sobre temas muitas vezes distantes de seu universo de saber, desconectados do mundo atual e tão artificiais, que acabam por inibir o ato da escritura. Se a escola tradicional não conseguia dar conta de ensinar redação ao aluno de modo que ele pudesse produzir seus textos com mais consciência do uso da língua, a era digital pode e deve promover esse feito. Com as ferramentas digitais de Revisão do MS Word, é possível indicar com balões de comentários e controle de alterações os desvios gramaticais, as inadequações lexicais, as falhas na trama textual e todos os critérios de avaliação do texto redigido pelo aluno.

Antes de demonstrar a metodologia de comentário dos textos, chamamos atenção para a indicação de signos orientadores. Nos exemplos a seguir, buscamos apontar o(s) signo(s) que funciona $(\mathrm{m})$ como marca(s) do fato linguístico em foco. Quer-se demonstrar com isso a possibilidade de compreensão dos mecanismos verbais com relativa facilidade, uma vez que, na maioria dos casos, tem-se marcas para orientar a identificação e a classificação adequadas.

Começa-se o trabalho mostrando textos com estruturação apropriada, de modo que seja favorecida a identificação e discussão do fato linguístico a observar. Procura-se mostrar para o estudante que há sempre uma ou mais formas da língua que funcionam como signos orientadores do raciocínio e que, quando colocados no local adequado, facilitam a compreensão por parte do interlocutor (leitor, intérprete etc. - o nome varia segundo a teoria eleita). No exemplo a seguir, destaca-se como produzir uma explicação:

Meu filho, eu sei que você aí, tão cheio de vida e de entusiasmo, não vai compreender isto. Mas tome nota do que eu digo porque um dia você concordará comigo: bom mesmo é escada rolante. [grifos nossos]

Fragmento de "Bom mesmo", de Luiz Fernando Veríssimo. In http://www.pensador.info/p/cronicas_de_luiz_fernando_verissimo/1/

\footnotetext{
${ }^{4}$ Seguimos a orientação de Simões (2007) que entende por signos icônicos os representativos, fundados na similaridade, de fundo analógico e por indiciais os indutores, fundados na contiguidade, consecutivos.
} 
Tabela 1: Esquema para discussão do processo de elaboração da expressão

\begin{tabular}{|c|c|c|c|}
\hline SUJEITO & PREDICADO & ORAÇÃO EXPLICATIVA & SIGNO ORIENTADOR \\
\hline (oculto) & Tome nota do que eu digo & Porque um dia concordará comigo & Verbo no futuro \\
\hline
\end{tabular}

O aluno será alertado para o fato de que a explicação pode distinguir-se da causa apesar da uma organização textual equivalente (às vezes idêntica) - a partir do tempo verbal empregado na oração subordinada - aquela que funciona como termo da oração principal. Vamos ao exemplo:

O norte-americano James Stacy, de 81 anos, pode pegar 90 dias de cadeia por reparar um buraco no asfalto próximo à sua casa em Akron, no estado de Ohio (EUA), segundo reportagem do "Akron Beacon Journal". [grifamos]

$$
\text { Portal G1 - 27/05/09 - 14h00 - Atualizado em 27/05/09 - 14h00 } 5
$$

Neste exemplo, a expressão da causa se dá por meio de uma oração reduzida de infinitivo. Veja-se o esquema:

Tabela 2

\begin{tabular}{|c|c|c|c|}
\hline SUJEITO & PREDICADO & ORAÇÃO CAUSAL & $\begin{array}{c}\text { SIGNO } \\
\text { ORIENTADOR }\end{array}$ \\
\hline $\begin{array}{c}\text { O norte-americano James } \\
\text { Stacy, de 81 anos, }\end{array}$ & $\begin{array}{c}\text { Pode pegar 80 dias de } \\
\text { cadeia }\end{array}$ & $\begin{array}{c}\text { Por reparar um buraco no } \\
\text { asfalto próximo à sua } \\
\text { casa (...) }\end{array}$ & $\begin{array}{c}\text { Ordem dos eventos: } \\
\text { 1) reparar o buraco } \\
\text { 2) ameaça de prisão }\end{array}$ \\
\hline
\end{tabular}

O jornalista teria, pelo menos, seis opções de organização do período para expressar a causa do conflito relatado: o conserto do buraco.

Tabela 3

\begin{tabular}{|c|c|c|c|}
\hline $\begin{array}{l}\text { ORAÇÃO } \\
\text { PRINCIPAL }\end{array}$ & $\begin{array}{l}\text { ORAÇÃO } \\
\text { CAUSAL }\end{array}$ & $\begin{array}{c}\text { ORAÇÃO } \\
\text { PRINCIPAL EM } \\
\text { ORDEM INVERSA }\end{array}$ & SIGNO ORIENTADOR \\
\hline $\begin{array}{l}\text { James Stacy pode } \\
\text { pegar } 90 \text { anos de } \\
\text { cadeia }\end{array}$ & $\begin{array}{l}\text { Por reparar um } \\
\text { buraco }\end{array}$ & & Por + infinitivo \\
\hline $\begin{array}{l}\text { James Stacy pode } \\
\text { pegar } 90 \text { anos de } \\
\text { cadeia }\end{array}$ & $\begin{array}{l}\text { Porque reparou } \\
\text { um buraco }\end{array}$ & & Porque + verbo no passado \\
\hline $\begin{array}{c}\text { James Stacy pode } \\
\text { pegar } 90 \text { anos de } \\
\text { cadeia }\end{array}$ & $\begin{array}{l}\text { Já que reparou } \\
\text { um buraco }\end{array}$ & & Já que + verbo no passado \\
\hline \multirow[t]{2}{*}{$\begin{array}{c}\text { James Stacy pode } \\
\text { pegar } 90 \text { anos de } \\
\text { cadeia }\end{array}$} & $\begin{array}{l}\text { Visto ter } \\
\text { reparado um } \\
\text { buraco }\end{array}$ & & Visto + locução verbal no passado \\
\hline & $\begin{array}{c}\text { Como reparou o } \\
\text { buraco }\end{array}$ & $\begin{array}{l}\text { James Stacy pode pegar } 90 \\
\text { dias de cadeia }\end{array}$ & $\begin{array}{c}\text { Como + verbo no passado + Oração } \\
\text { principal em ordem inversa }\end{array}$ \\
\hline
\end{tabular}

\footnotetext{
${ }^{5}<$ http://g1.globo.com/Noticias/PlanetaBizarro/0,MUL1168538-6091,00-

APOSENTADO+PODE+SER+CONDENADO+POR+REPARAR+BURACO+EM+ASFALTO.html>
} 


\begin{tabular}{|l|c|c|c|}
\hline & $\begin{array}{c}\text { Como reparasse } \\
\text { um buraco }\end{array}$ & $\begin{array}{c}\text { James Stacy pode pegar 90 } \\
\text { dias de cadeia }\end{array}$ & $\begin{array}{c}\text { Como + verbo no imperfeito do } \\
\text { subjuntivo + Oração principal em } \\
\text { ordem inversa }\end{array}$ \\
\hline
\end{tabular}

Vale destacar que a forma como vimos discutindo os textos oferece ao aluno, simultaneamente, instruções de organização textual e informações gramaticais, visando a demonstrar ao estudante que o domínio da gramática é necessário não só para que se torne capaz de praticar leituras com compreensão, assim como organizar sua expressão com consciência na escolha e na organização das formas linguísticas.

Antes de entrarmos a demonstrar os procedimentos de intervenção no texto discente, decidimos dialogar com Dutra (2012):

Em oposição ao paradigma formalista, o funcionalismo linguístico procura analisar o texto associando o material linguístico de que é constituído internamente aos aspectos do contexto de sua produção e leitura. Essa postura teórica reflete-se na sala de aula promovendo uma abordagem que privilegia a reflexão sobre o funcionamento da língua, sobre o trabalho com a gramática e sobre sua integração com o texto (DUTRA, 2012, p. 256).

Assim sendo, nossa proposta metodológica para o ensino da redação ganha dimensão funcional, uma vez que procura desenvolver, no aluno, um raciocínio específico sobre a escolha das formas da língua a ativar, segundo suas metas comunicativas. Enfatizamos que nada na língua é gratuito e que a seleção e a combinação dos signos na produção textual demanda atenção para os efeitos que se quer causa no leitor com o que se vai expressar. Portanto, as relações de coesão e coerência, tão discutidas nos últimos anos da década de 1990, ganha novas dimensões, a partir da constatação da relevância da relação entre a forma e o conteúdo, recuperando, assim, pressupostos saussurianos e associando-os aos postulados peircianos relativos à semiose: ou seja, a produção do sentido de uma expressão (independentemente do código em que se materialize) resulta de uma articulação entre o texto e o contexto. Este por sua vez se biparte, levando-nos a considerar o contexto de produção (o autor e o cenário da enunciação) e o contexto de leitura (o leitor e seu entorno).

Concluímos esta seção com palavras de Dutra (2012):

Para que o objetivo comunicativo de quem escreve seja alcançado pelo leitor, é preciso que o autor do texto mobilize uma gama de conhecimentos além do código especificamente. É preciso que ele mobilize outros conhecimentos referentes à língua, conhecimentos referentes aos gêneros, ao mundo de uma forma geral e às diferentes situações de comunicação.

Diferentemente da concepção de língua como código e de escrita como um exercício de combinar palavras e frases para formar um texto, hoje a escola precisa ver o texto escrito como mais uma forma de interação social (instrumento de comunicação). Apesar de a ideia não ser absolutamente nova - a transformação conceitual começou a ocorrer na década de 70, com Bakhtin -, ela ainda não provocou a mudança desejada nas práticas escolares. São poucas as iniciativas de um trabalho com leitura e escrita que considera o discurso uma prática social e uma forma de interação. (DUTRA, 2012, p. 248). 


\section{Instruções semiótico-gramaticais para aperfeiçoar a expressão escrita}

Segundo Morris (1976), a sintaxe é o mais desenvolvido dos ramos da semiótica. É também o plano de análise que oferece maior margem de objetividade, uma vez que se estrutura a partir de relações lógicas, pelas quais os signos se entrelaçam intimamente, de modo que operações sobre conjuntos iniciais propiciam operar com os demais conjuntos, porque assim constituem um sistema.

Pautados na dimensão sintática da semiose, os princípios lógico-gramaticais orientam a construção de todas as frases de uma língua. Em decorrência, todos os signos do sistema estarão sujeitos às regras de formação e às regras de transformação das quais são geradas as formas representacionais do pensamento no código verbal. Todavia, para além da organização sintática da língua em padrões lógicos, esse mesmo sistema disponibiliza ao falante possibilidades de ordenação psicológica, ou seja, a marcação do texto se solta dos princípios lógico-sintáticos originais e se submete a outra marcação, de natureza afetiva, emocional.

Sumarizando, temos que a organização sintática básica se constitui por:

Tabela 4

\begin{tabular}{|c|l|}
\hline TIPIFICAÇÃO & \multicolumn{1}{c|}{ DEMONSTRAÇÃO } \\
\hline Regras de formação & Ex. O sujeito concorda com o verbo em número e pessoa. \\
\hline Regras de transformação & $\begin{array}{l}\text { Ex. A oração reduzida pode ser transformada em outra } \\
\text { desenvolvida equivalente. }\end{array}$ \\
\hline Ordem lógica & $\begin{array}{l}\text { Sujeito, predicado e objetos (SVO). } \\
\text { Ex. José (sujeito) estuda (predicado) sintaxe (complemento) } \\
\text { aos sábados e domingos (adj. adv.). }\end{array}$ \\
\hline Ordem psicológica & $\begin{array}{l}\text { Enfatiza dados segundo valores emocionais inscritos nos } \\
\text { signos, subvertendo a ordem lógica. } \\
\text { Ex. Aos sábados e domingos (adj. Adv.), José (sujeito) estuda } \\
\text { (predicado) sintaxe (complemento). }\end{array}$ \\
\hline
\end{tabular}

Esse preâmbulo vem reiterar que a formulação verbal da expressão implica domínio sintático articulado com os domínios vocabular e enciclopédico. Isso porque a sintaxe coordena os encaixes entre os termos; o domínio vocabular permite ao falante escolher a forma mais apropriada para presentificar sua ideia; por fim, o domínio enciclopédico é o que situa os sujeitos num tempo histórico e viabiliza a produção de enunciados que possam ser compreendidos pelo interlocutor potencial previsto para o texto.

Transcrevemos aqui o esclarecimento de Simões e Oliveira apresentados no Congresso da ABRALIN (UFSC, 2011):

Observem-se os dados a partir dos quais foi construída a proposta de trabalho.

Problema: Dificuldades de leitura e de produção textual pela falta de domínio gramatical e lexical, por parte dos alunos do ensino médio, segundo dados apurados em pesquisas nos textos para interpretação e nas redações dos processos seletivos para o terceiro grau.

Atitude: Modificação no protocolo de ensino da gramática, conduzindo a identificação de fatos e fenômenos gramaticais a partir de práticas de leitura e produção textual. Participação da Universidade como agente de renovação da prática de ensino de língua portuguesa. (UFSC, 2011). 
O processo é iniciado com a produção de uma tabela de comentários, feita a partir das intervenções já realizadas pelo professor nas redações de seus alunos. A tabela serve de base para as futuras correções, quando realizadas em documento Word. Observe-se que se procuram articular dados de natureza estrutural com a normatização gramatical, com vista a objetivar os comentários que virão a ser inseridos nos textos dos estudantes. Esta tabela vai sendo alimentada sempre que o professor realizar algum comentário diferente nas redações (o que é frequente, porque os textos trazem marcas individualizantes). Como um banco de dados para consulta e utilização sistemática em textos de todo tipo, os comentários devem ser o mais abrangentes possível, a fim de servirem de instrução generalizada para todos os casos que se submetam à mesma regra. Observe-se o que circulamos abaixo, é uma demonstração do modo como operamos com os textos dos comentários.

Figura 1 - Tabela de comentários

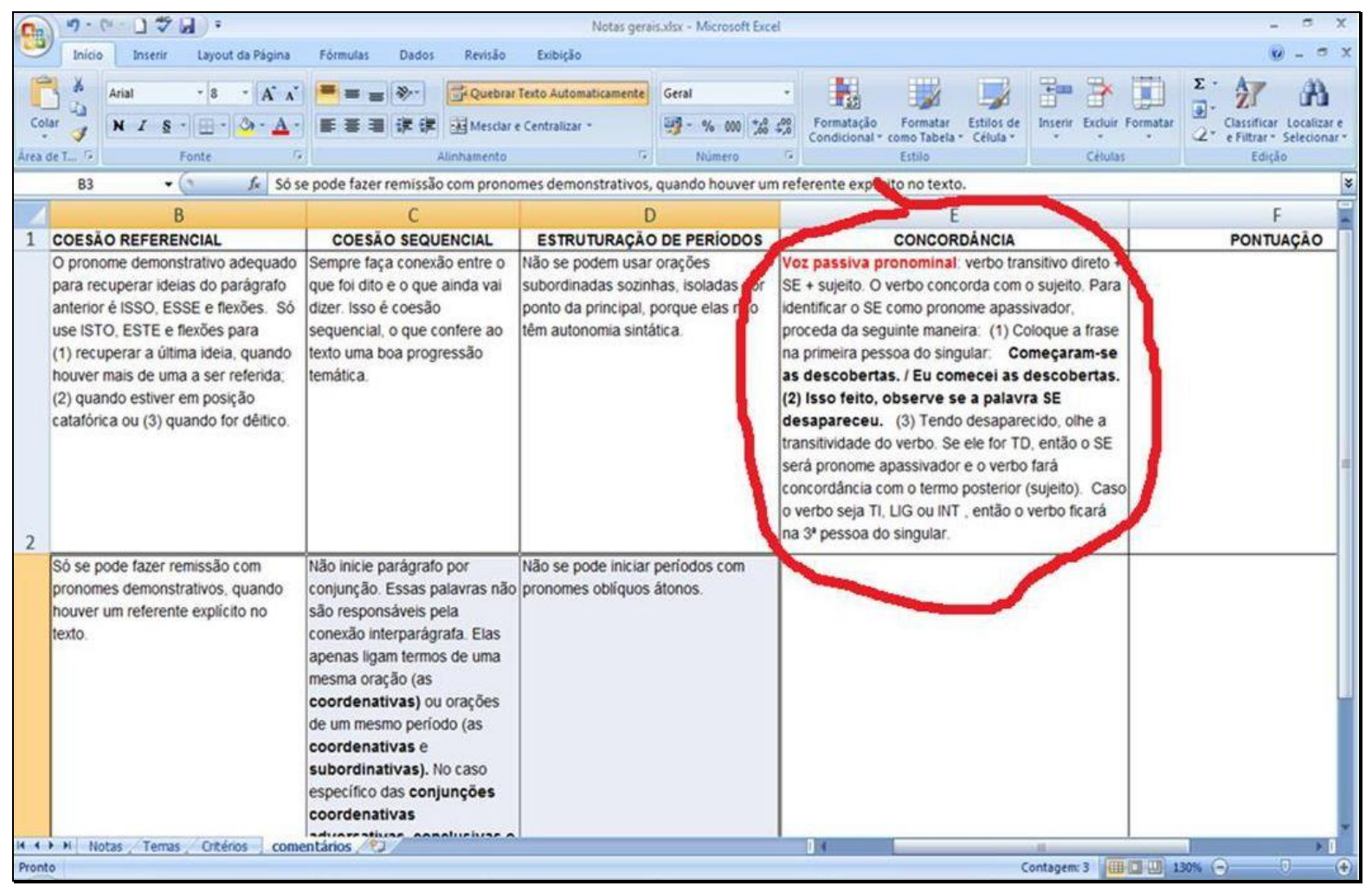

Passemos à demonstração do processo de intervenções, isto é: o modo como corrigimos as redações dos alunos e as ferramentas digitais que usamos para esse fim.

Visto que o computador e a Internet são uma prática já dada como parte integrante do espaço educativo, criamos um site com possibilidade de "download" e "upload" de redações discentes, cujo objetivo é a correção com comentários, operando com suporte da Plataforma Moodle, por meio da qual podemos separar os alunos por turmas de acordo com o concurso a que se destinam e graus de competência linguística.

Como operamos, então?

Primeiro, pedimos aos alunos que redijam seus textos em documento Word (tipo *.doc, *.docx ou *.rtf), estratégia que insere nossas aulas nas Novas Tecnologias da Informação e Comunicação (NTIC). Depois de redigir seu texto, os sujeitos os enviam para nossa plataforma, para que sejam corrigidos. 
A seguir mostram-se redações comentadas, para que sejam compreendidos os meios de correção e de instrução gramatical.

Figura 2 - Imagem da intervenção no texto discente

\begin{tabular}{|c|c|}
\hline \multirow{9}{*}{ 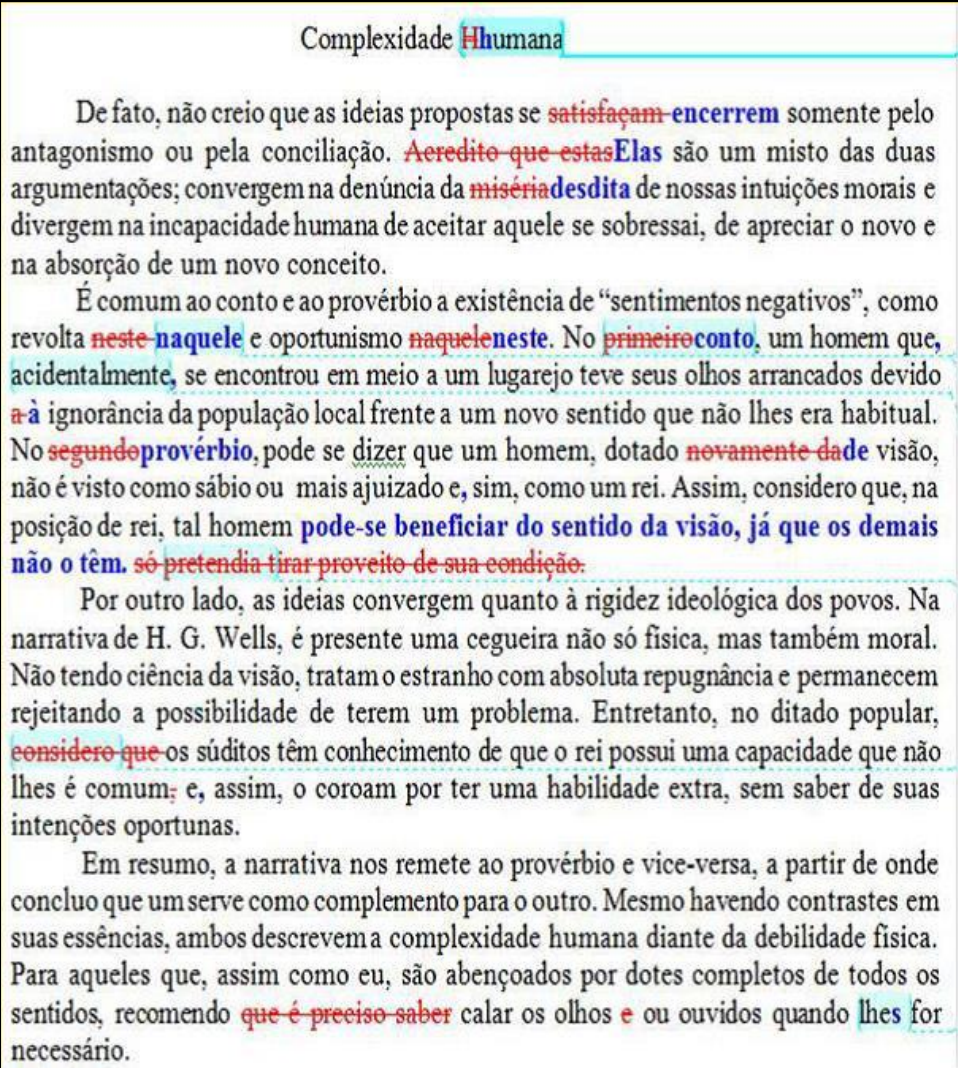 } & $\begin{array}{l}\text { [RR1] Comentário: Somente a primeir } \\
\text { palavra do tinulo tem letra maxisculal }\end{array}$ \\
\hline & \multirow[b]{2}{*}{$\begin{array}{l}\text { [RR2] Comentário: NESTE serefére } \\
\text { ao último referente (provérbio)e } \\
\text { NAQUELE, ao referente mais distante } \\
\text { (conto). }\end{array}$} \\
\hline & \\
\hline & \\
\hline & \\
\hline & \\
\hline & \multirow[t]{2}{*}{$\begin{array}{l}\text { [RR6] Comentário: Não use esta } \\
\text { estrategia mais de una vez. Fica cansativo } \\
\text { repettivo. PERIGOSOIII }\end{array}$} \\
\hline & \\
\hline & \\
\hline
\end{tabular}

Figura 3- Imagem de intervenção em outro texto

\begin{tabular}{|c|c|}
\hline \multirow{5}{*}{$\begin{array}{l}\text { O que você está esperando? } \\
\text { um problema epidêmico que, cresce cada dia mais, pois sofre grande /influenciat_influência } \\
\text { do trafied_tráfico_de drogas que domina ideologicamente_a mentalidade coletiva das dos } \\
\text { periferias urbanas. }\end{array}$} & Formatado: Centralizado \\
\hline & \\
\hline & \\
\hline & \\
\hline & $\begin{array}{l}\text { U. Comentário: Todas as } \\
\text { nas sto acentuadas }\end{array}$ \\
\hline \multicolumn{2}{|l|}{$\begin{array}{l}\text { A letalidade dessa droga derivada da cocaína impressiona os mais céticos olhares, } \\
\text { chegando ao assustador um terço de óbitos de seus usuários. Enquanto autoridade, o } \\
\text { governo deve tratar essa questão como problema de saúde pública, e, enquanto }\end{array}$} \\
\hline \multirow{3}{*}{ 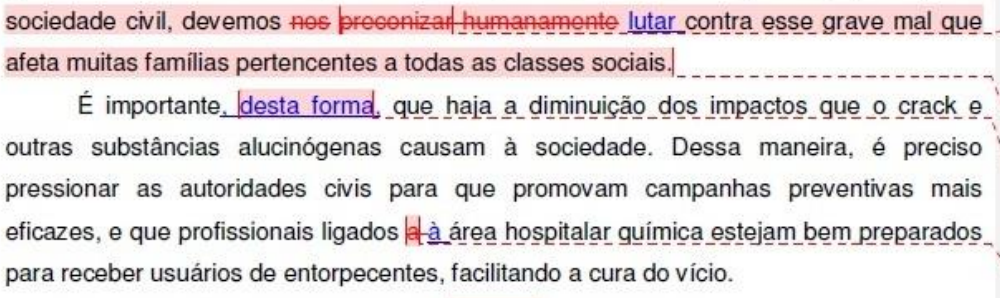 } & 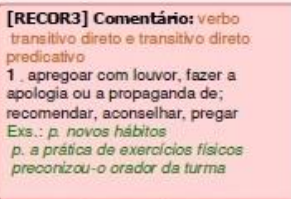 \\
\hline & $\begin{array}{l}\text { [RECOR4] Comentário: Mal } \\
\text { construito. }\end{array}$ \\
\hline & $\begin{array}{l}\text { [RECOR5] Comentário: Atenç̧io à } \\
\text { coessio. }\end{array}$ \\
\hline \multirow{3}{*}{$\begin{array}{l}\text { A solução desse grave problema, portantol requer investimentos na área da saúde } \\
\text { e ações sociais que acabem com o tráfico de drogas no brasil Brasil. Essa realidade } \\
\text { ainda nos parece um pouco distante, pois o número de comunidades dominadas pelos } \\
\text { criminosos que viabilizam a compra desses produtos tem crescido cada vez mais. Porém, }\end{array}$} & $\begin{array}{l}\text { [RECOR6] Comentário: Alençio ao } \\
\text { empre go da crase. }\end{array}$ \\
\hline & $\begin{array}{l}\text { [RECOR7] Comentário: Vide } \\
\text { comentario 05. }\end{array}$ \\
\hline & $\begin{array}{l}\text { [RECOR8] Comentário: ATENÇÃo } \AA \\
\text { ORTOGRAFU }\end{array}$ \\
\hline nosso dever como eidadão cidadãos consciente-conscientes_é agir juntamente $€$ em as às & $\begin{array}{l}\text { [RECOR9] Comentário: Alençăo à } \\
\text { concordincia. }\end{array}$ \\
\hline $\begin{array}{l}\text { autoridades }+ \text { pois a melhoria da qualidade de vida e } \\
\text { a sociedade está também em nossas mãos. }\end{array}$ & \\
\hline
\end{tabular}


Apontamos os desvios, no texto do aluno, de forma que:

- o que se retira, aparece tachado (riscado);

- o que se insere, aparece em cor distinta do texto original;

- o que se comenta, aparece nos balões à direita do texto, com as iniciais do professor que corrigiu (RR, RECOR, nos exemplos dados).

Importante esclarecer que nosso trabalho se realiza por meio digital e explora recursos do MS Word, cuja ferramenta de alterações controladas permite que se opere com código de cores, que nas publicações impressas perdem efeito em função da predominância da escala cinza, uma vez que a impressão em policromia é muito dispendiosa. Essa nota se faz relevante porque também são icônicas as cores que representam as marcações no processo de intervenção, a que convencionamos da seguinte forma: azul nas inserções; vermelho nos cortes e substituições; balões de comentário também coloridos. Com essas marcações, os sujeitos podem analisar seus textos, observado as escolhas lexicais, as estruturas frasais, os mecanismos de coesão, a ortografia, a pontuação e todas as competências linguísticas necessárias à elaboração de um texto claro, coeso, coerente e, portanto, emoldurado pela norma gramatical.

Ao receber de volta o texto comentado, os sujeitos passam à segunda etapa do processo: a retextualização. Nesse momento, eles são levados a reescrever o texto, considerando os comentários e correções feitas pelo tutor/professor.

Com esse procedimento, as aulas ficam mais claras, mais objetivas, e os alunos se interessam pela apreensão das regras gramaticais, por perceberem a importância destas na estruturação dos enunciados para atingir eficientemente seu propósito comunicativo.

Como resultado desse trabalho, temos, em classes, alunos:

- $\quad$ mais conscientes do uso da língua, com capacidade de discutir e analisar os problemas de seus próprios textos;

- $\quad$ preparados para iniciar o trabalho de leitura mais consciente dos textos literários e não literários;

- com domínio das instruções gramaticais para as atividades de leitura e produção textual.

Esse tipo de trabalho - que vendo sendo testado desde 2002 por Simões, e por Oliveira desde 2005 —, voltado para a competência redacional, pode ser aplicado em turmas preparatórias para processos seletivos (de níveis médio e superior), em textos técnicos, científicos e acadêmicos, em turmas de produção de redações criativas (ensino fundamental), em treinamento para produção de textos literários, em cursos de redação administrativa ou oficial etc. Em cada caso, serão privilegiadas as variedades linguísticas adequadas aos gêneros textuais prevalentes e aos critérios de avaliação de cada banca examinadora.

Com todos esses pressupostos, sentimos a necessidade de mergulhar não só em textos teóricos, mas também em documentos oficiais de ensino que pudessem nos servir de apoio na formulação de uma proposta de ensino cujo escopo de trabalho pudesse ser aplicado com eficiência nas aulas de Língua Portuguesa com foco na expressão escrita. Sabe-se que a Redação, nessa nova era de concurso vestibular, se tornou o instrumento de avaliação mais importante. No Exame Nacional do Ensino Médio (ENEM), por exemplo, é a única prova que possibilita ao candidato tirar nota mil (valendo então $50 \%$ do total de pontos). Explica-se: todas as provas, somados os pontos, valem dois mil pontos, distribuídos como se vê no gráfico a seguir. 
Figura 4 - Gráfico de pontuação das provas do ENEM

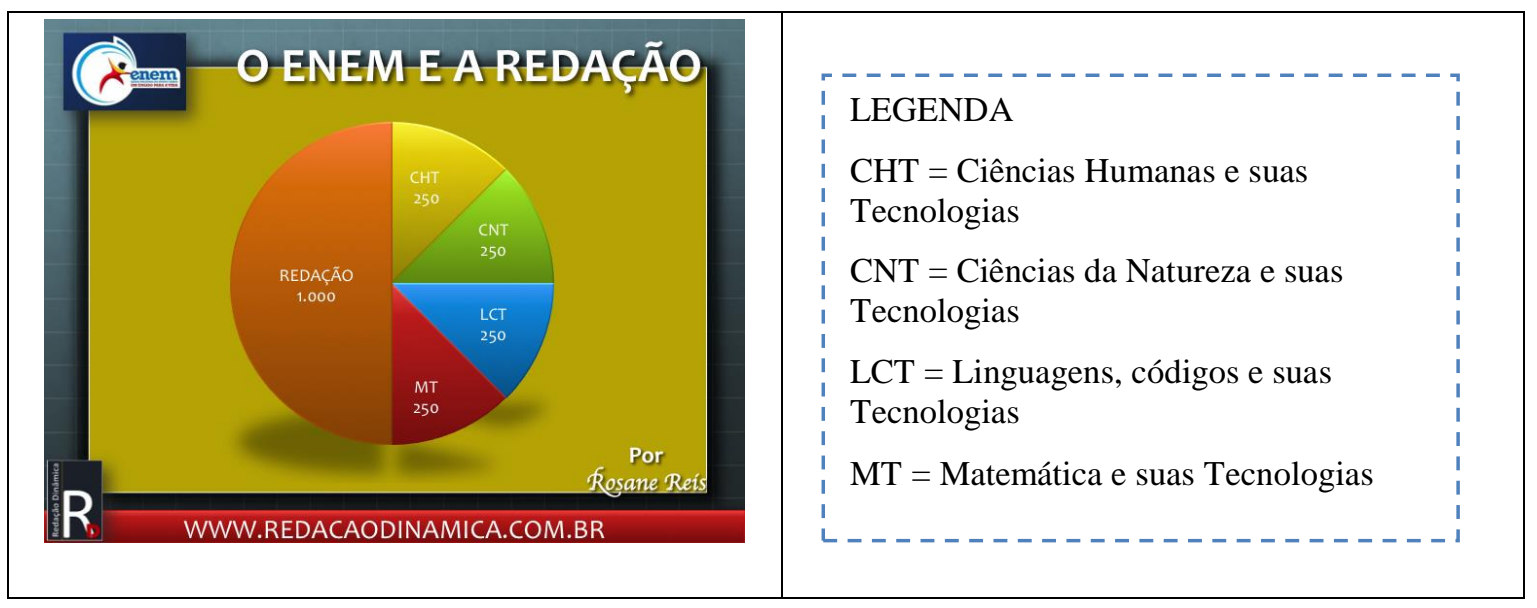

Cada uma das provas objetivas (CHT, CNT, LCT e MT) contém 45 questões, totalizando, assim, 180 questões de múltipla escolha, com 5 itens cada uma. Para tirar mil pontos nessa etapa, portanto, o candidato deverá acertar as 180 questões, o que até os dias de hoje não se viu acontecer. Mas é viável, para o estudante comprometido com a aprendizagem da língua portuguesa, conseguir mil pontos em Redação. E aqui está descrito o que nos motivou a buscar, nos documentos oficiais do Ministério da Educação (MEC), interseção com nossa base teórica e pesquisa, a fim de criar um trabalho que nos desse segurança na preparação de estudantes para boa parte dos concursos que contemplam o texto escrito como forma de avaliação e seleção.

Nosso trabalho vem sendo orientado pelas competências avaliadas no ENEM (cf. OLIVEIRA, 2014):

Tabela 5 - Competências redatoras segundo Manual do ENEM

\begin{tabular}{|l|}
\hline \multicolumn{1}{|c|}{ COMPETÊNCIAS REDATORAS } \\
\hline Competência 1: Demonstrar domínio da modalidade escrita formal da língua portuguesa. \\
\hline $\begin{array}{l}\text { Competência 2: Compreender a proposta de redação e aplicar conceitos das várias áreas de } \\
\text { conhecimento para desenvolver o tema, dentro dos limites estruturais do texto dissertativo- } \\
\text { argumentativo em prosa. }\end{array}$ \\
\hline $\begin{array}{l}\text { Competência 3: Selecionar, relacionar, organizar e interpretar informações, fatos, opiniões e } \\
\text { argumentos em defesa de um ponto de vista. }\end{array}$ \\
\hline $\begin{array}{l}\text { Competência 4: Demonstrar conhecimento dos mecanismos linguísticos necessários para a construção } \\
\text { da argumentação. }\end{array}$ \\
\hline $\begin{array}{l}\text { Competência 5: Elaborar proposta de intervenção para o problema abordado, respeitando os direitos } \\
\text { humanos. }\end{array}$ \\
\hline
\end{tabular}

O que se espera de um trabalho didático focado nas competências acima descritas é que o aluno seja capaz de produzir um texto claro, objetivo e direto, empregando vocabulário variado e preciso, diferente do que utiliza quando fala, seguindo as regras estabelecidas pela modalidade escrita formal da língua portuguesa. Portanto, diz a matriz de referência, o texto dissertativo-argumentativo escrito deve atender aos seguintes requisitos (cf. OLIVEIRA, 2014): 
Tabela 6 - Requisitos textuais conforme Matriz ENEM

\begin{tabular}{|c|}
\hline REQUISITOS DO TEXTO DISSERTATIVO-ARGUMENTATIVO \\
\hline 1. ausência de marcas de oralidade e de registro informal; \\
\hline 2. precisão vocabular; e \\
\hline 3. obediência às regras de: \\
\hline 3.1. concordância nominal e verbal; \\
\hline 3.2. regência nominal e verbal; \\
\hline 3.3. pontuação; \\
\hline 3.4. flexão de nomes e verbos; \\
\hline 3.5. colocação de pronomes oblíquos (átonos e tônicos); \\
\hline $\begin{array}{l}\text { 3.6. grafia das palavras (inclusive acentuação gráfica e emprego de letras maiúsculas e } \\
\text { minúsculas); e }\end{array}$ \\
\hline 3.7. divisão silábica na mudança de linha (translineação). \\
\hline
\end{tabular}

É possível, como vimos constatando, gerar iconicidade no texto, portanto garantindo sua eficácia comunicativa, quando usamos adequadamente o léxico e a gramática da língua, levando em conta que a organização textual deve refletir uma relação com a organização de uma visão de mundo.

Vale lembrar que O. M. Garcia (1995) põe como epígrafe de Comunicação em Prosa Moderna, o aforismo: "Aprenda a escrever, aprendendo a pensar".

\section{Palavras finais}

Entendemos que a língua nacional é a base da formação intelectual dos sujeitos de uma nação, por isso vimo-nos ocupando com projetos de pesquisa que têm por objeto maior a comunicação escrita formal. Por que isto? Principalmente pela necessidade de apetrecharemse os indivíduos para a leitura e escrita que lhes fortalecerá a cidadania, por se tornarem leitores mais críticos e escritores mais proficientes, prontos para se inserirem na sociedade de prestígio. Este projeto, pois, tem a finalidade de ter implementadas as tecnologias aplicadas à correção de redações, a fim de elevar o nível verbal escrito de discentes por todo o país.

Com essas ideias, busca-se realizar um trabalho em que as variedades linguísticas, os gêneros textuais e as condições de produção do texto sejam sempre consideradas, para que os comentários apostos aos textos produzidos pelos discentes não venham a resultar em desestímulo para suas futuras produções.

Segundo Correia (2012),

A teoria das semioses orientadas e das semioses criativas constitui um suporte teórico adequado para uma análise da competência semiótica e para a observação das relações entre os processos de semiose e evolução da cognição (CORREIA, 2012, p. 94).

A teoria da iconicidade verbal se baseia exatamente nessa hipótese teórica. E na crença dos efeitos didático-pedagógicos desse potencial orientador da compreensão humana é que vimos trabalhando no aperfeiçoamento desta proposta teórico-metodológica. 
Dessa forma, pretende-se, com o ensino de redação e gramática nos moldes apresentados, contribuir não só para o enriquecimento do repertório do estudante, mas principalmente para o desenvolvimento de suas competências de leitura e de produção textual. Vocabulário mais amplo e habilidade de avaliação da maior ou menor iconicidade dos itens léxicos selecionados são dados relevantes para o progresso expressional dos alunos. E é com esse material que o emissor construirá seus enunciados de forma mais consciente, com os quais poderá produzir textos inteligíveis, em decorrência da iconicidade diagramática sintagmática neles presentes.

Nesse viés, um ensino de redação e gramática com perspectivas semióticas, como se comprovou nesta oportunidade, possui relevância assegurada na pedagogia moderna, uma vez que assim se pode operar segundo possíveis intenções comunicativas compatíveis com o projeto de texto, que a seu turno define gênero e variante linguística.

A nosso ver, o ensino da língua materna, com base em competências e habilidades, vem derrubar preconceitos e barreiras, uma vez que trabalha com o útil e o essencial que, embora ainda envolva muito conhecimento, não será um conhecimento estéril, distante das práticas cotidianas do sujeito. O que se propõe é um ensino que objetive, de fato, transformar o aluno em cidadão, com plenas capacidades de expressão, oral ou escrita, em especial na variedade padrão da língua portuguesa, por ser esta a que se vai buscar na escola. Porque, se há algum projeto político eficaz de tornar o Brasil uma nação soberana, este depende de cidadãos participantes. Assim sendo, é papel da escola oferecer educação linguística eficiente de modo a propiciar o desenvolvimento intelectual dos sujeitos nacionais e garantir-lhes melhores condições de vida, já que, num país capitalista, quem fala bem, em geral, come bem.

\section{Referências}

CORREIA, C. M. de C. Competência semiótica, percepção e desenvolvimento das interpretações. In: SIMÕES, D. (Org.) Língua portuguesa e ensino: reflexões e propostas sobre a prática pedagógica São Paulo: Factash Editora, 2012, p. , 91-122.

DUTRA, V. L. R. Competências e habilidades para a produção de textos. In: SIMÕES, D. (Org.) Língua portuguesa e ensino: reflexões e propostas sobre a prática pedagógica São Paulo: Factash Editora, 2012, p. 235-253.

ECO, U. Obra Aberta. Forma e indeterminação nas poéticas contemporâneas. São Paulo: Perspectiva, 1969.

GARCIA, O. M. Comunicação em prosa moderna. $16^{\mathrm{a}}$ ed. Rio de Janeiro: Fundação Getúlio Vargas, 1995.

NÖTH, W. Panorama da semiótica: de Platão a Peirce. São Paulo: Annablume, 1995.

OLIVEIRA, R. R. Semiótica e ensino: competências e habilidades para a expressão escrita em língua portuguesa. Tese (Doutorado). Rio de Janeiro, 2014. Programa de Pós-graduação em Letras. Universidade do Estado do Rio de Janeiro.

SIMÕES, D. Lexicogramática e iconicidade na escolha de palavras e expressões. In: GERHARDT, A. F. L. M. Ensino-aprendizagem na perspectiva da Linguistica Aplicada. São Paulo: Pontes, 2013, p. 53-77. 
Semiótica \& Ensino: Alfabetização pela imagem. Rio de Janeiro: Dialogarts, 2009b.

Sintaxe e organização icônica do texto. In: ASSIS, E. et all (Org.) INTERtextos. Goiânia: EdPUC-GO, 2012, v.1, p. 57-80

; OLIVEIRA, R. R. O ensino de redação, EAD e as competências e habilidades dos PCN mediados pela iconicidade. Atas do Congresso Internacional da Abralin. João Pessoa: Ideia, 2011.

Iconicidade Verbal: Teoria e Prática. Rio de Janeiro: Dialogarts., 2009.

OLIVEIRA, R. R. Iconicidade verbal: aplicações no ensino de línguas. In: OSÓRIO, P.; BERTINETTI, F. M. Teorias e usos linguísticos: Aplicações ao Ensino do Português Língua Não Materna. (no prelo). Lisboa: Lidel. - Edições Técnicas, 2014. 